\title{
Effectiveness of a Conditioning Program on Amateur Female Marathon Runners
}

\author{
Apoorva Santosh Kolhatkar'1, Sandeep Babasahed Shinde ${ }^{2}$ \\ ${ }^{1}$ Department of Physiotherapy, Krishna Institute of Medical Sciences Deemed to be \\ University, Karad, Maharashtra, India. ${ }^{2}$ Department of Physiotherapy, Krishna Institute of \\ Medical Sciences Deemed to be University, Karad, Maharashtra, India.
}

\section{ABSTRACT}

\section{BACKGROUND}

There is a sudden rise in the participation of middle-aged women in marathons across India without proper knowledge about how to prepare for these marathons. This leads to rise in injuries in them like low back pain, knee pain, stress fractures, urinary incontinence etc., some of which can easily be avoided. There is a need to find out a suitable conditioning program for these participants that will target problems affecting this age group and gender specifically. The objective of this study was to determine the effect of conditioning program on post run physical functioning in female amateur marathon runners. Pain Assessment, DOMS, Modified Borg Scale were used for assessing the individuals.

\section{METHODS}

In this comparative study, 52 amateur female marathon runners, were randomly allocated into two groups with 26 runners in each group. We evaluated pain and exertion using pain assessment and Borg Scale. Occurrence of incontinence was assessed by asking a simple 'yes' or 'no' question. Delayed onset muscle soreness (DOMS) was assessed using pain pressure threshold (PPT) 24 hrs. post run.

\section{RESULTS}

There was a significant effect of the conditioning program on these female runners compared to administration of no conditioning at all. There was a reduction of pain in all the components of the pain scale $(p=<0.001)$. Exertion of the trained runners was also less $(p=<0.001)$ as well as in the occurrence of incontinence $(p=<0.0430)$. PPT was also substantially increased in them $(\mathrm{p}=<0.001)$.

\section{CONCLUSIONS}

The conditioning program administered to amateur female marathon runners was effective in reducing their risk of injuries and problems related to women's health that occur while running a marathon.

\section{KEY WORDS}

Amateur Female Marathon Runners, Pain, Borg Scale, Delayed Onset Muscle Soreness, Pressure Pain Threshold
Corresponding Author: Dr. Sandeep Babasaheb Shinde, Associate Professor, Faculty of Physiotherapy, Krishna Institute of Medical Sciences, Deemed to be University, Karad, Maharashtra, India. E-mail: drsandeepshinde24@gmail.com

DOI: $10.14260 /$ jemds/2020/444

How to Cite This Article: Kolhatkar AS, Shinde SB. Effectiveness of a conditioning program on amateur female marathon runners. J. Evolution Med. Dent. Sci. 2020;9(29):2040-2044, DOI: 10.14260/jemds/2020/444

Submission 28-01-2020,

Peer Review 09-06-2020,

Acceptance 15-06-2020,

Published 20-07-2020.

Copyright (C) 2020 JEMDS. This is an open access article distributed under Creative Commons Attribution License [Attribution 4.0 International (CC BY 4.0)] 


\section{BACKGROUND}

Marathon running is a rapidly growing sport of interest for middle-aged, non-athletic individuals. Awareness about health and fitness, both mental and physical is rising among them. There is a sudden surge in the efforts made to make people aware about lifestyle related disorders. This has led to more and more number of people wanting to practice some kind of exercise in order to improve their fitness as well. Equipped with inadequate knowledge and an increased drive to exercise, they enrol themselves for marathons. This happens as the easiest to start and accessible for all method to embark on their fitness journey is to run. Absolutely no equipment except for a pair of good sports shoes is all that is required. Also, these marathons are highly advertised and sponsored and thus seem like a more attractive form of exercise for these amateur enthusiasts compared to other sports. Thus, the popularity of running has increased many fold among this community. A recent study shows that, the participation of amateur runners in marathon events has increased 25 -fold in the past two decades.[1] Another study shows that the age of the participants has also increased and is the highest till date, with an average age of 39.3 years. ${ }^{[2]}$ Also, there is a surprisingly high peak in the participation of women in marathons. In 2018, $50.24 \%$ of the runners were female.[2]

This surge in women's participation in the world of sports, especially running has led to a lot positive changes in women's mental and physical wellbeing. However, this does not come without it's negative effects too. Among such individuals are women, who are normally exposed to running only when the company that they are working at asks them to participate in marathons or their group of friends decides to run a marathon for fun. Such women do not have enough time to train for such marathons. These women find it extremely difficult to take out time for exercise from their daily schedule let alone follow a regular exercise program. They also do not have proper guidance as to what conditioning program they should follow. There is an abundance of conditioning programs available on the internet that they can use as an inspiration for their training. This can make deciding which exercises to choose and how hard to work out even more difficult. Furthermore, these women do not have adequate knowledge regarding the biomechanics and physiology of the body that is necessary to make these decisions.

So, they resort to simple exercises that they are informed about either by their friends or something that they've read on the internet. There is generally no proper warm up and cool down. Also, there is no consistency in their training. This predisposes them to unnecessary injuries even before they've run the marathon or may make them more vulnerable to injuries during the run.

Moreover, since there is a lack of guidance, they are unaware of the proper method to perform an exercise which may in turn reduce their efficacy. This may lead to injuries early on in their training and may thus discourage them from participating in the marathon altogether. Another, very commonly observed scenario is when suddenly these women realize that they need to focus more on their fitness and train vigorously for marathons. This leads to over exhaustion and numerous injuries that may hamper their health for the long run. These are just some of the issues that these women will generally encounter while preparing for a marathon. Apart from these general situations affecting them, health related issues in these women is a whole new chapter to discuss. There are various hormonal changes that occur in women of this age. Some changes that have a serious impact on their desire to run are, loss of elasticity in the breast tissue, leaking bladder, low back ache, reduction in bone mass density, menstrual abnormalities, knee pain and menstruation.

With progressing age, there is a loss of collagen from the tissues which leads to saggy breasts. This increases the strain on the shoulders and upper back leading to back ache. This problem is not only seen in women with larger breasts but also in women with comparatively smaller breasts. Running is a high impact sport which leads to constant impact on the breast tissues in female runners which in turn increases the strain on the shoulder and back. Most of the middle-aged women are multi-parous. This leads to weakening of the pelvic floor muscles. Even if the women has a caesarean section, the weight of the baby during pregnancy adds stress over the pelvic floor. Age is again a factor that weakens the ligaments supporting the bladder. Running causes stress over the bladder and thus many women experience leakage during running. A study showed that $38 \%$ of multi-parous women experienced leakage and $28 \%$ of nulliparous women experienced leakage. [3]

These women also have weakened abdominal musculature due to pregnancy and a relatively sedentary lifestyle. Pregnancy leads to an increase in the lumbar lordosis. Also, if they have undergone a caesarean section, their core muscle become weak. Working at jobs that promote a sedentary lifestyle will also in turn cause weakness of the abdominal musculature. Thus, there is an increased risk of low back ache. ${ }^{[4]}$ Middle-aged women also experience a reduction in their bone mass density.[5] This occurs due to depletion of oestrogen and an improper diet.[6] Thus, reduced bone mass density, also known as osteopenia put the woman at a high risk of incurring stress fractures.

Menstruation causes excessive fatigue and abdominal cramping. This may hamper with their ability to run and thus discourage their participation. Many women also experience excessive low back ache during menstruation.[7] Thus, it is necessary to deal with this issue as well. Thus, there are numerous issues regarding women's health that need to be addressed before we can consider them ready for a marathon. These issues have a huge impact on a woman's mindset as well as their physical wellbeing. These issues can be embarrassing or if worse, can be disabling for certain women. By addressing these problems, we can ensure that such amateur women who have a desire to run have a safe and healthy experience. This ensures that not only are no women discouraged from participating but also more and more women feel empowered and encouraged to run. ${ }^{[8]}$ Hence, the health of the nation's most prevalent population will improve to a huge extent and thus the future of this nation as well. According to my knowledge, there are not many if any conditioning programs which focus on these issues regarding women's health. Thus, it is necessary to devise such a conditioning program that addresses all these issues. This study was intended to focus on finding prophylactic measure to lessen the risk of injuries in these women, in turn improving their performance as well as participation. 


\section{METHODS}

This comparative study was carried out at Karad, DistrictSarata. In this comparative study, 52 amateur female marathon runners, randomly allocated into the two groups with 26 each, Previous studies by Samruddhi Shashikant Barve and Arati Mahishale shown 26 female participants. Minimum subjects required with $95 \%$ confidence and $80 \%$ power is $\mathrm{n}=26$, Hence minimum 29 subjects in either group should be studied. In this interventional study injury prone trainee cadets were randomly allocated by using random allocation software in two groups of 26 each with advanced training program A total of 52 individuals were included in this study who fulfilled the inclusion criteria of being female, between the ages of 35-45 years, leading a relatively sedentary lifestyle and having never participated in a marathon before. They were divided into two equal groups namely Group A and Group B using the simple random sampling method. The procedure was explained, and consent was taken from them.

Here, the individual's areas of pain were noted using pain assessment. The individual was asked to mark their regions of pain on a previously prepared list of 5 significant areas of the body (low back, knee, upper back, breast and other). Their rate of perceived exertion was also recorded with the help of Modified Borg Scale. Occurrence of incontinence was also noted using a simple 'yes' or 'no' question.

Pain pressure threshold was recorded $24 \mathrm{hrs}$ later to objectively quantify occurrence of delayed onset muscle soreness. ${ }^{8}$ For the lower limb, PPT at the calves, hamstrings and the quadriceps of both the legs were measured, in the upper limb the biceps brachi muscle was used and for the back trapezius and latissimus dorsi was used. The mean score of all these muscles were calculated and were used to represent the respective individual. After collection of data, the results were compared, and statistical analysis was done.

\section{Procedure}

After getting ethical approval from institutional ethical committee, this study was carried out at Karad. Informed consent was taken from the subjects who fulfilled inclusion criteria. In this comparative study, 52 amateur female marathon runners, randomly allocated into the two groups with 26 each by using random allocation software.

Group A received walking for 30 mins every day, pelvic bridging combined with Kegel's exercises with a hold time of $15 \mathrm{sec}$ and 3 repetitions for a total of 3 sets, knee push-ups for 10 repetitions for a total of 3 sets, superman row with a hold time of $10 \mathrm{sec}$ and 3 repetitions for a total of 3 sets. These exercises were allocated for the 1st week with a rest day on the last day i.e. 7 th day of the week. For the 2 nd week, walking for 20 mins and jogging for 5 mins daily, planks with a hold time of $15 \mathrm{sec}$ and 2 repetitions for a total of 2 sets, reverse planks with a hold time of $15 \mathrm{sec}$ and 2 repetitions for a total of 2 sets, dumbbell chest press $(0.5 \mathrm{Kg})$ in long lever for 10 repetitions for a told of 3 sets and squats combined with Kegel's exercises for 10 repetitions for a total of 3 sets, superman row with a hold time of $10 \mathrm{sec}$ and 3 repetitions for a total of 3 sets. Rest day was be the last day of the week. For the 3rd week, walking for 20 mins and jogging for $15 \mathrm{sec}$ daily, planks with a hold time of $30 \mathrm{sec}$ and 2 repetitions for a total of 2 sets, reverse planks with a hold time of $30 \mathrm{sec}$ and 2 repetitions for a total of 2 sets, superman row with a hold time of $20 \mathrm{sec}$ and 3 repetitions for a total of 3 sets, dumbbell chest press $(1 \mathrm{Kg})$ in long lever for 10 repetitions for a told of 3 sets and squats combined with Kegel's exercises for 15 repetitions for a total of 3 sets. Rest day was be the last of the week. For the 4 th week, jogging for 35 mins daily, planks with a hold time of $30 \mathrm{sec}$ and 2 repetitions for a total of 2 sets, reverse planks with a hold time of $30 \mathrm{sec}$ and 2 repetitions for a total of 2 sets, superman row with a hold time of $20 \mathrm{sec}$ and 3 repetitions for a total of 3 sets, dumbbell chest press $(1 \mathrm{Kg})$ in long lever for 10 repetitions for a told of 3 sets and squats combined with Kegel's exercises for 15 repetitions for a total of 3 sets. Rest day was the last day of the week.

Group B was the control group which consisted of women who had not received any form of conditioning program.

\section{Statistical Analysis}

Was done to compare the results of both group A and B in accordance with the pain assessment. Unpaired t-test was done for all the components of the pain scale individually. Low back pain had a p-value of 0.0047 which is very significant, Knee pain had a p-value of 0.0014 which is very significant, upper back pain had a p-value of 0.0071 which is also very significant, Breast pain had a p-value of 0.0033 which is very significant and other pain had a p-value of 0.2629 which is not significant. One-way ANOVA test presented a p-value of pain, $<0.05$.

\section{RESULTS}

\begin{tabular}{|c|c|c|c|c|c|c|c|c|c|}
\hline & & Grol & up $A$ & & & Grou & up B & & \\
\hline $\begin{array}{l}\text { Age } \\
\text { Group }\end{array}$ & 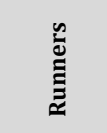 & de & $\begin{array}{l}\text { के } \\
+1 \\
\equiv \\
\text { 刃ँ } \\
\sum^{2}\end{array}$ & 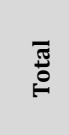 & 氖 & ஓ & $\begin{array}{l}\text { के } \\
+1 \\
\tilde{\Xi} \\
\sum^{ \pm}\end{array}$ & సٓ유 & $\underset{7}{3}$ \\
\hline $35-39$ & 16 & $\begin{array}{c}61.53 \\
\%\end{array}$ & $\begin{array}{l}37 \pm \\
1.46\end{array}$ & & 16 & $\begin{array}{c}61.53 \\
\%\end{array}$ & $\begin{array}{c}36.94 \pm \\
1.29\end{array}$ & & \\
\hline $40-45$ & 10 & $\begin{array}{c}38.46 \\
\%\end{array}$ & $\begin{array}{c}1.40 \\
42.5 \pm \\
1.65\end{array}$ & 26 & 10 & $\begin{array}{c}38.46 \\
\%\end{array}$ & $\begin{array}{c}41.6 \pm \\
1.51\end{array}$ & 26 & 52 \\
\hline & & Grol & up A & & & Grou & ap B & & \\
\hline BMI & Runners & $\%$ & $\underset{\text { SD }}{\text { Mean } \pm}$ & Total & Runners & $\%$ & $\begin{array}{c}\text { Mean } \pm \\
\text { SD }\end{array}$ & Total & : \\
\hline Normal & 14 & $\begin{array}{c}53.85 \\
\%\end{array}$ & $\begin{array}{l}22.78 \\
\pm 1.51\end{array}$ & & 14 & $\begin{array}{c}53.85 \\
\%\end{array}$ & $\begin{array}{c}22.28 \pm \\
1.11\end{array}$ & & \\
\hline $\begin{array}{c}\text { Over } \\
\text { weight }\end{array}$ & 9 & $\begin{array}{c}34.62 \\
\%\end{array}$ & $\begin{array}{c}26.83 \pm \\
1.40\end{array}$ & 26 & 8 & $\begin{array}{c}30.77 \\
\%\end{array}$ & $\begin{array}{c}27.28 \pm \\
1.31\end{array}$ & 26 & 52 \\
\hline G-1 Obese & 3 & $\begin{array}{c}11.54 \\
\%\end{array}$ & $\begin{array}{c}30.77 \pm \\
0.64\end{array}$ & & 4 & $\begin{array}{c}15.38 \\
\%\end{array}$ & $\begin{array}{c}30.9 \pm \\
0.35\end{array}$ & & \\
\hline & & Gro & up A & & & Grou & Ip B & & \\
\hline Occupation & Runners & & $\%$ & Total & Runners & & $\%$ & Total & $\stackrel{\pi}{0}$ \\
\hline Housewife & 12 & & $.15 \%$ & & 11 & 42. & $31 \%$ & & \\
\hline Working & 14 & $\begin{array}{r}53 \\
\text { Grot }\end{array}$ & $\begin{array}{l}.85 \% \\
\text { up A }\end{array}$ & 26 & 15 & $\begin{array}{r}57 . \\
\text { Grou }\end{array}$ & $\begin{array}{l}69 \% \\
\text { lp B }\end{array}$ & 26 & 52 \\
\hline Parity & Runners & & $\%$ & Total & Runners & & $\%$ & Total & $\stackrel{\pi}{0}$ \\
\hline Multiparous & 17 & & $.38 \%$ & & 15 & & $69 \%$ & & 57 \\
\hline Primigravida & 9 & & $62 \%$ & 26 & 11 & & $31 \%$ & 26 & 52 \\
\hline
\end{tabular}




\begin{tabular}{|c|c|c|c|c|c|c|c|}
\hline \multirow[b]{2}{*}{ Pain } & \multicolumn{3}{|c|}{ Group A } & \multicolumn{3}{|c|}{ Group B } & \multirow[b]{2}{*}{ Total } \\
\hline & $\begin{array}{c}\text { No. of } \\
\text { Runners }\end{array}$ & $\%$ & Total & $\begin{array}{c}\text { No. of } \\
\text { Runners }\end{array}$ & $\%$ & Total & \\
\hline $\begin{array}{l}\text { Low } \\
\text { Back }\end{array}$ & 08 & $30.77 \%$ & \multirow{6}{*}{26} & 17 & $65.38 \%$ & \multirow{6}{*}{26} & \multirow{5}{*}{52} \\
\hline Knee & 06 & $23.08 \%$ & & 16 & $61.54 \%$ & & \\
\hline $\begin{array}{c}\text { Upper } \\
\text { Back }\end{array}$ & 04 & $15.38 \%$ & & 13 & $50.00 \%$ & & \\
\hline Breast & 02 & $7.69 \%$ & & 11 & $42.31 \%$ & & \\
\hline Others & 05 & $19.23 \%$ & & 12 & $46.15 \%$ & & \\
\hline Total & 25 & - & & 69 & - & & 94 \\
\hline \multicolumn{8}{|c|}{ Table 2. Distribution of Pain According to Regions } \\
\hline
\end{tabular}

\begin{tabular}{|cc|}
\hline Group & Mean \pm SD \\
A & $3.15 \pm 0.61$ \\
B & $5.46 \pm 0.90$ \\
\hline Table 3. Distribution of Borg Score in Group A and Group B \\
\hline
\end{tabular}

\begin{tabular}{|cccc|}
\hline Group & Incontinent Runners & Total & Percentage \\
A & 1 & 26 & $3.85 \%$ \\
B & 6 & 26 & $23.07 \%$ \\
Total & $\mathbf{7}$ & $\mathbf{5 2}$ & $\mathbf{1 3 . 4 6 \%}$ \\
\hline Table 4. Prevalence of Incontinence in Group A and Group B \\
\hline
\end{tabular}

\begin{tabular}{|cc|}
\hline Group & Mean \pm SD \\
A & $2.76 \pm 0.51$ \\
B & $1.98 \pm 0.65$ \\
\hline Table 5. Distribution of Delayed Muscle Soreness (PPT) \\
in Group A and Group B \\
\hline
\end{tabular}

\begin{tabular}{|ccccc|}
\hline $\begin{array}{c}\text { Outcome } \\
\text { Measures }\end{array}$ & $\begin{array}{c}\text { Group A } \\
\text { Mean } \pm \text { SD }\end{array}$ & $\begin{array}{c}\text { Group B } \\
\text { Mean } \pm \text { SD }\end{array}$ & t- Value & P- Value \\
Pain & $3.31 \pm 0.57$ & $6.69 \pm 0.77$ & 3.130 & $<0.01$ \\
Low Back & $3.91 \pm 0.44$ & $7.04 \pm 0.38$ & 3.443 & $<0.01$ \\
Knee & $3.94 \pm 0.83$ & $6.86 \pm 0.27$ & 2.817 & $<0.05$ \\
Upper Back & $2.94 \pm 0.83$ & $>0.05$ \\
Other & $3.11 \pm 0.48$ & $5.81 \pm 0.76$ & 0.9865 & $>0.001$ \\
BORG Score & $3.15 \pm 0.61$ & $5.46 \pm 0.90$ & 14.798 & $<0.001$ \\
Incontinence & $2.89 \pm 0.71$ & $4.11 \pm 0.11$ & 1.233 & $>0.05$ \\
PPT & $2.76 \pm 0.51$ & $1.98 \pm 0.65$ & 2.982 & $<0.001$ \\
\hline \multicolumn{5}{c|}{ Table 6. Association between Outcome Measures Used to } \\
\multicolumn{5}{c}{ Assess Group A and Group B } \\
\hline
\end{tabular}

\section{DISCUSSION}

The aim of this study was to study and find the effectiveness of conditioning program on female amateur marathon runners. The objectives of this study were to determine the effect of this conditioning program on post-run physical functioning in these runners. We also wanted to compare the effects of such a program with a group of runners who did not participate in the conditioning program. An effort to find the association between the effects of the conditioning program with the effects of not administering any conditioning program was made. In this study, 52 women who participated in the same marathon were chosen. They were divided into two groups, A and B respectively where group A was administered a conditioning program designed by us and group $B$ underwent no form of training.

Pain assessment was used to note their areas of pain. The discomfort or pain experienced by the runners post marathon were divided into 5 categories. There were 4 primary categories based on the region of pain, namely Low Back, Knee, Upper Back and Breast with a fifth category which included other regions of the body. This shows that the conditioning program had a significant role in reducing the risk of injury and pain in these amateur middle-aged women, compared to regular training. There was a significant impact on back pain as well which supports the use of this conditioning program.

Borg Scale was used to measure the level of exertion of the runners. The scores for the both the groups were calculated with the mean score for group A being 3.15 and that for group B 5.46. Thus, mean exertion of runners in group A is less compared to that of those in group B.

Statistical analysis was done and the difference between the mean score of both the groups was compared. The p-value for unpaired t-test is $<0.0001$ which is extremely significant and for One-way ANOVA testis $<0.001$ which is very significant.

A study by Maul, I., Läubli, T., Oliveri, M. et al. found that Supervised physical training effectively improved functional capacity and decreased LBP. ${ }^{9}$ Another study by Thomas KS, Muir KR, Doherty M, Jones AC, O'Reilly SC, Bassey EJ concluded that A simple home based exercise programme can significantly reduce knee pain. ${ }^{[10]}$ A recent study by. Barve SS, Mahishale A, found that Structured Exercise Programme was effective in reducing pain, tenderness and improving Quality Of Life in adult females with cyclic mastalgia.[11] A study by Haj Ghanbari B, Yamabayashi C, Buna TR, Coelho JD, Freedman KD, Morton TA, Palmer SA, Toy MA, Walsh C, Sheel AW, Reid WD concluded that a structured exercise program led to an increase in the respiratory capacity of runners.[12]Thus it is safe to assume that administration of the conditioning program led to a decrease in the exertion levels of the runners.

A single question asking to state the presence or absence of urinary incontinence was used to assess the pelvic floor strength. From Group A, 1 (3.85\%) runner experienced some form of urinary incontinence and from Group B, 6 (23.07\%) runners experienced some form of urinary incontinence. Statistical analysis was done to compare the difference in the runners who experienced incontinence. Unpaired t-test had a p-value of 0.0430 which is significant and One-way ANOVA test has a p-value of $>0.05$ which is not significant.

Bø K, Hagen RH, Kvarstein B, Jørgensen J, Larsen S, Burgio KL conducted a study that concluded that PFM exercise for female SUI is highly effective.[13] Another study by $\mathrm{B} \emptyset \mathrm{K}$ also concluded that there was a significant effect of exercises on improving urinary continence. ${ }^{[14]}$ Hence, this conditioning program may be effective in reducing the risk of incontinence in such runners. Further detailed analysis needs to be done on this aspect. Pressure Pain Threshold was used to measure the level of DOMS in the runners. The scores for the both the groups were calculated with the mean score for group A being 2.76 and that for group B 1.98. Thus, mean severity of DOMS in runners in group A is less compared to that of those in group B. Statistical analysis was done and the difference between the mean score of both the groups was compared. The $\mathrm{p}$-value for unpaired t-test is 0.0154 which is significant and for One-way ANOVA testis $<0.001$ which is very significant.

A study by Szymanski DJ found that here was a significant effect of continuous eccentric exercise 1-6 weeks before running on the occurrence of DOMS.[15]Therapeutic exercise programme is effective in improving functional status, grip strength and perceived health in adults with early Rheumatoid arthritis.[16] This study found a significant difference in the results of all the parameters that were used to assess both Group A and Group B of runners post completion of the marathon. There was significant reduction in the pain experienced by the former group compared to the latter. The same can be said about the rate of their perceived exertion as well as about the experiences of urinary incontinence.

This study is extremely important as the number of women participating in marathons has increased manifold but at the 
same time women centric conditioning programs are not implemented. It sheds light on the need for construction of various conditioning programs that are suitable for different populations. Middle-aged women face more difficulty while running compared to the youth. Problems such as low back pain due to poor core strength, knee pain due to osteoarthritis, stress fractures due to osteoporosis, urinary incontinence due to weak pelvic floor muscles, pre-menopausal signs and symptoms are just some of the issues faced by this population. Our conditioning program focuses on strengthening the core as well as the pelvic floor, the pectorals, performing weight bearing exercises specifically to strengthen the knee musculature and exercises to improve and regulate the lung capacity of these women.

Thus, not only generic strengthening and endurance training but a focus on factors revolving specifically around this age group of women in our study will help reduce their risk of injury and in turn promote an increase in their participation.

\section{CONCLUSIONS}

There is a significant effect of our conditioning program on amateur female runners. The effect was most profound on low back pain, then knee pain, breast pain, and finally upper back pain. The perceived exertion of individuals who had undergone training was significantly lower compared to those in the control group. There was a significant reduction in the occurrence of incontinence as well. The pressure pain threshold also noted an increase in the trained runners.

\section{Conflict of Interest}

There were no conflicts of interest in this study

\section{Ethical Clearance}

Ethical clearance was taken from institutional committee of Krishna Institute of Medical Sciences, Deemed to be University, Karad.

\section{Source of Funding}

Krishna Institute of Medical Sciences Deemed to be University, Karad.

\section{REFERENCES}

[1] O'Keefe JH, Franklin B, Lavie CJ. Exercising for health and longevity vs peak performance: different regimens for different goals. Mayo Clin Proc 2014;89(9):1171-5.

[2] Brown N, White J, Brasher A, et al. The experience of breast pain (mastalgia) in female runners of 2012 London
Marathon and its effect on exercise behaviour. Br J Sports Med 2014;48(4):320-5.

[3] de Mattos Lourenco TR, Matsuoka PK, Baracat EC, et al. Urinary incontinence in female athletes: a systematic review. Int Urogynecol J 2018;29(12):1757-63.

[4] Costill D, Fox E. Energetics of marathon running. Medicine and Science in Sports 1969;1(2):81-86.

[5] Sjodin B, Svedenhag J. Applied physiology of marathon running. Sports Med 1985;2(2):83-99.

[6] Costill DL. Physiology of marathon running. JAMA 1972;221(9):1024-9.

[7] Fredericson M, Mishra AK. Epidemiology and aetiology of marathon running injuries. Sports Med 2007;37(45):437-9.

[8] Cheung K, Hume P, Maxwell L. Delayed onset muscle soreness: treatment strategies and performance factors. Sports Med 2003;33(2):145-64.

[9] Maul I, Läubli T, Oliveri M, et al. Long-term effects of supervised physical training in secondary prevention of low back pain. Eur Spine J 2005;14(6):599-611.

[10] Thomas KS, Muir KR, Doherty M, et al. Home based exercise programme for knee pain and knee osteoarthritis: randomised controlled trial. BMJ 2002;325(7367):752.

[11] Barve SS, Mahishale A. Effect of a structured exercise program on pain and quality of life in adult females with cyclic mastalgia: an experimental study. Indian J Health Sci Biomed Res 2019;12(1):79-84.

[12] HajGhanbari B, Yamabayashi C, Buna TR, et al. Effects of respiratory muscle training on performance in athletes: a systematic review with meta-analyses. J Strength Cond Res 2013;27(6):1643-63.

[13] Bø K, Hagen RH, Kvarstein B, et al. Pelvic floor muscle exercise for the treatment of female stress urinary incontinence: III. effects of two different degrees of pelvic floor muscle exercises. Neurourology and Urodynamics 1990;9(5):489-502.

[14] Bø K. Pelvic floor muscle training is effective in treatment of female stress urinary incontinence, but how does it work? Int Urogynecol J Pelvic Floor Dysfunct 2004;15(2):76-84.

[15] Szymanski DJ. Recommendations for the avoidance of delayed-onset muscle soreness. Strength \& Conditioning Journal 2001;23(4):7-13.

[16] Shinde SB, Varadharajulu G. Effect of therapeutic exercise programme in adults with early rheumatoid arthritis. Indian J Physiotherapy and Occupational Therapy 2017;11(3):76-80. 